\title{
Perancangan Alat Bantu Home Scaffolding
}

\author{
Agly Prasta Dewansyah, Rindra Yusianto, Jazuli \\ Teknik Industri, Fakultas Teknik, Universitas Dian Nuswantoro Semarang \\ Jl. Nakula I No. 5-11, Semarang, Jawa Tengah, 50131 \\ Email: aglyprasta@gmail.com
}

\begin{abstract}
Scaffolding is a tool commonly used in installation processes that are similar in shape to stairs. Based on survey results to existing scaffolding users, it is concluded that it needs to be redesign because it is too heavy and inflexible. This is why many scaffolding users are not satisfied. In this research, will be designed a scaffolding that suits the needs of consumers by using rational methods and anthropometric approach. The use of rational methods aims to obtain the objectives, functions, details, and selection of scaffolding materials, while the anthropometric approach is used to determine the size of the scaffolding according to Indonesian posture. From the research that has been done, the results obtained that the scaffolding to be designed has to can be set height, can be folded so that it can save space, lightweight, easy to carry and safe to use. Testing of designed scaffolding gives results that the new design is able to withstand loads of up to 2500 Newtons $(254.94 \mathrm{Kg})$ making it safe to use for 2-3 people.
\end{abstract}

Keywords: Anthropometry, Ergonomy, Rational method, Scaffolding

\begin{abstract}
Abstrak
Scaffolding adalah suatu alat yang biasa digunakan dalam proses instalasi yang mirip bentuknya dengan tangga. Berdasarkan hasil survey kepada pengguna scaffolding yang ada saat ini, didapatkan kesimpulan bahwa perlu adanya redesign karena terlalu berat dan tidak fleksibel. Hal inilah yang menyebabkan banyaknya pengguna scaffolding tidak puas. Dalam penelitian ini, akan dirancang suatu scaffolding yang sesuai dengan kebutuhan konsumen dengan menggunakan metode rasional serta pendekatan antrhopometri. Penggunaan metode rasional bertujuan untuk mendapatkan tujuan, fungsi, detil, serta pemilihan material scaffolding, sementara pendekatan anthropometri digunakan untuk menentukan ukuran dari scaffolding tersebut sesuai dengan postur tubuh orang Indonesia. Dari penelitian yang telah dilakukan, didapatkan hasil bahwa scaffolding yang akan didesain harus dapat diatur ketinggiannya, dapat dilipat sehingga dapat menghemat tempat, ringan, mudah dibawa serta aman untuk digunakan. Pengujian terhadap scaffolding yang telah dirancang memberikan hasil bahwa desain yang baru ini mampu menahan beban hingga 2500 Newton $(254,94 \mathrm{Kg})$ sehingga aman bila digunakan untuk 2-3 orang.
\end{abstract}

Kata kunci: Anthropometri, Ergonomi, Metode Rasional, Scaffolding

\section{Pendahuluan}

Di era yang modern sangat mempengaruhi kehidupan manusia, salah satunya adalah desain rumah. Desain rumah di era modern berbeda dengan desain rumah yang lama. Aksesoris rumah inilah yang menjadi unggulan dari desain rumah modern, seperti lampu gantung, kaca hias, gypsum eternit. Namun sebagian besar aksesoris rumah berada di ketinggian yang diluar jangkauan tangan manusia, karena rumah modern sendiri di desain dengan model tinggi agar terlihat megah.

Memasang/instalasi aksesoris rumah modern tentunya membutuhkan alat bantu, salah satunya adalah alat bantu seperti tangga. Tetapi ketika pemasangan aksesoris rumah seperti kaca, lampu gantung, ternit atau AC menggunakan tangga akan mempersulit proses pengerjaan, karena pekerja di haruskan untuk bekerja berdiri, sedangkan intalasi aksesoris 
rumah membutuhkan waktu yang cukup lama dan ruang gerak yang cukup. Cara terbaik melakukan pekerjaan instalasi adalah menggunkan alat bantu yang mirip tangga, yaitu perancah atau yang sering di sebut sebagai scaffolding.

Scaffolding adalah suatu struktur sementara yang digunakan untuk menyangga manusia dan material dalam konstruksi atau perbaikan rumah dan bangunan-bangunan besar lainnya. Biasanya perancah berbentuk suatu sistem modular dari pipa atau tabung logam, meskipun juga dapat menggunakan bahan-bahan lain. Di beberapa negara Asia seperti RRC dan Indonesia, bambu masih digunakan sebagai perancah.

Dibalik peranan scaffolding yang begitu penting bagi proses pengerjaan bangunan, terdapat beberapa masalah yang sering timbul, pada umumnya adalah masalah waktu proses merakit dan kurangnya fleksibilitas ketinggian. Hal tersebut membuat pekerja harus menambahkan sendiri bambu atau kayu untuk menyesuaikan ketinggian yang cukup memakan waktu lama. Namun ada juga masalah lain yang terjadi yaitu penyimpanan part dari scaffolding sendiri sangat memakan tempat, karena memang part dari scafolding untuk satu tingkat saja sejumlah 5 .

Scaffolding yang ada di pasaran ada beberapa macam bentuk yaitu Scaffolding yang terbuat dari bambu yang hanya menjakau 2-3 meter (disebut juga andang), dan ada juga yang terbuat dari pipa (logam besi) yang dapat disusun tinggi. Namun masih terdapat kekurangan dalam model scaffolding yang ada pada saat ini yaitu pengaturan ketinggian yang kurang fleksibel, berat, repot dalam proses perakitan dan pelepasan, susah dipindahkan. Sehingga mengakibatkan munculnya keluhan para pekerja saat proses pengerjaan perbaikan rumah maupun pemasangan aksesoris rumah. Oleh karena itu, perlu segera dilakukan dengan lebih baik melalui penyesuaian mesin, alat dan perlengkapan kerja terhadap tenaga kerja yang dapat mendukung kemudahan, kenyamanan dan efisiensi kerja [1].

Tahap awal yang dilakukan yaitu dengan melakukan survey pendahuluan terhadap 81 responden yang pernah menggunakan scaffolding. Dengan adanya survey pendahuluan ini diharapkan hasil tersebut mewakili dari fungsi-fungsi yang dibutuhkan para pengguna scaffolding. Berdasarkan hasil olahan data survey sebanyak $82,50 \%$ responden menyatakan tidak puas dalam penggunaan scaffolding di rumah. Dari proses penggunaan scaffolding masih terdapat kendala yang dirasakan oleh responden diantaranya $22,22 \%$ responden menyatakan berat. Sebanyak $24,69 \%$ responden menyatakan mobilitas (pemindahan) dalam penggunaan susah di lakukan ketika sudah di rakit. Sebanyak 20,99\% responden menyatakan proses perakitan atau pemasangan scaffoldng membutuhkan waktu. Sebanyak 32,10\% responden menyatakan susah dalam menyesuaikan ketinggian, responden menyatakan ada solusi sementara yaitu dengan menambahkan kayu atau bambu, namun solusi yang diberikan dirasa belum maksimal. Dan sebanyak $78,75 \%$ responden menyatakan perlu adanya pembaruan desain scaffolding.

Desain produk merupakan salah satu unsur memajukan industri agar hasil industri produk tersebut dapat diterima oleh masyarakat, karena produk yang mereka dapatkan mempunyai kualitas baik,harga terjangkau,desain yang menarik,mendapatkan jaminan dan sebagainya [2]. Rancangan/desain adalah totalitas fitur yang mempengaruhi penampilan dan fungsi produk tertentu menurut yang diisyaratkan oleh pelanggan [3]. Ada banyak metode yang digunakan dalam melakukan perancangan/desain, salah satunya adalah metode rasional. Penggunaan metode ini digunakan untuk merepresentasikan presepsi konsumen, perancang dan teknisi mengenai kebutuhan yang dikehendaki ke dalam beberapa alternatif yang diperlukan. Metode rasional adalah metode yang menggunakan suatu urutan yang sistematis dalam setiap tahapan. Metode rasional mempunyai tujuan yaitu memperluas daerah penelitian untuk solusi potensial, atau menjadi fasilitator tim kerja dan kelompok pengambilan keputusan. Metode ini telah digunakan oleh Ramdhani [4] untuk mendesain alat pengupas kulit lunak mlinjo dan Susanto [5] untuk mendesain meja kerja untuk alat pres plastic. Metode ini diharapkan juga mampu digunakan untuk merancang alat bantu Home Scaffolding.

\section{Metode Penelitian}

Penelitian yang dilakukan peneliti dalam penyusunan laporan tugas akhir ini terletak di daerah Kota Semarang, di beberapa perumahan yang sedang diperbaiki maupun sedang dibangun. Subyek yang digunakan dalam penelitian ini adalah pekerja bangunan atau tukang ataupun pengguna scaffolding rumah dan bangunan standar. Sedangkan obyek yang 
diteliti adalah desain dan proses penggunaan scaffolding. Adapun alur proses penelitian ini dapat dilihat pada Gambar 1.

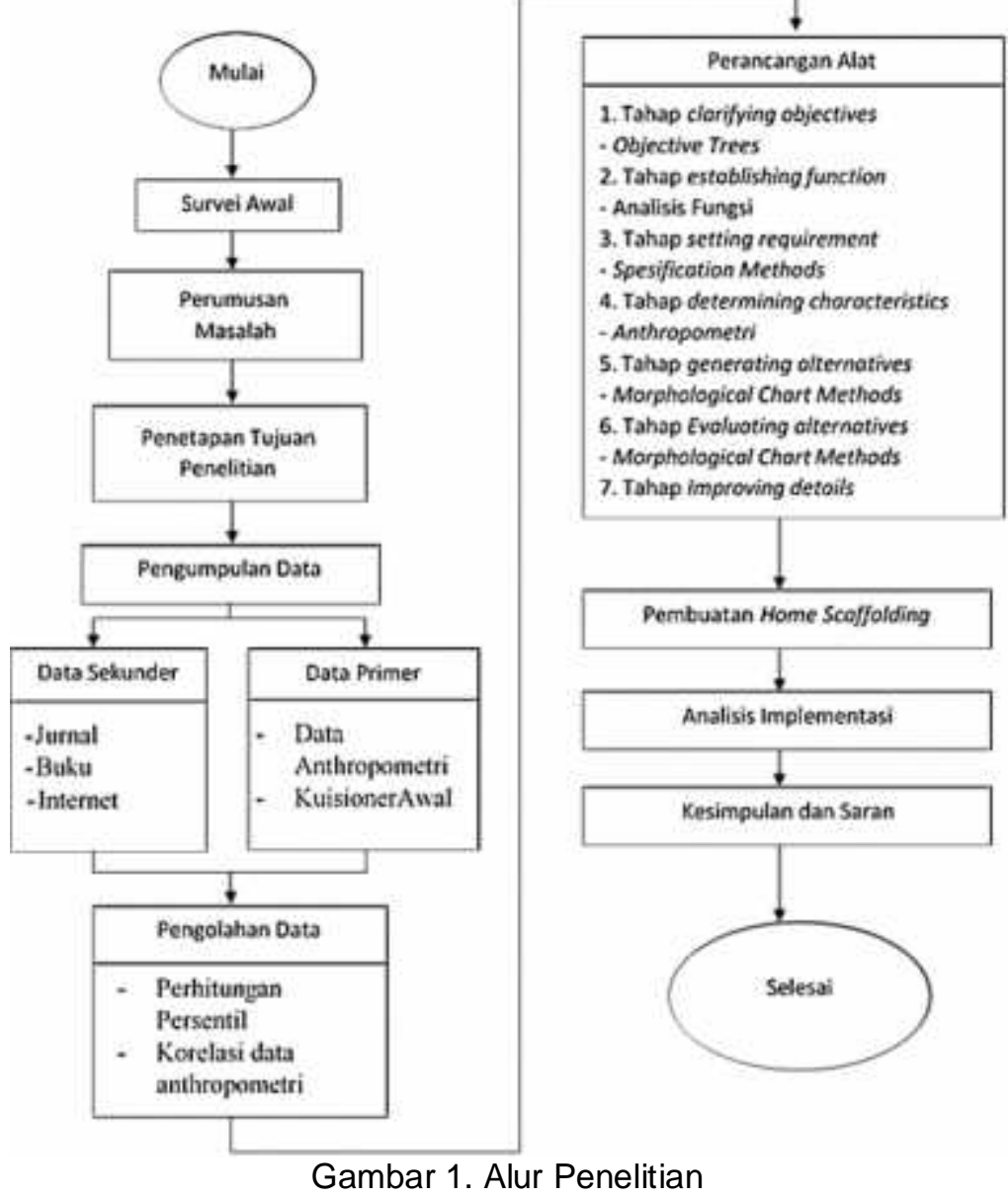

Penelitian dimulai dengan survei awal, kemudian perumusan masalah dan penetapan tujuan penelitian. Setelah itu, pengumpulan data dilakukan baik data primer maupun sekunder. Setelah data diperoleh, data kemudian diolah untuk dapat dibuat perancangan alat dengan menggunakan metode rasional. Setelah itu Home Scaffolding tersebut dibuat dan diimplementasikan untuk dianalisis kemudian diakhiri dengan penarikan kesmipulan dan saran.

\section{Hasil dan Analisis}

\subsection{Tahap Clarifying Objectives}

Pada tahap ini metode yang digunakan adalah metode objective tree. Metode ini bertujuan untuk menjelaskan tujuan dan sub tujuan dari perancangan dan juga menganalisis hubungan keduanya. Objectives tree untuk perancangan alat bantu Home Scaffolding dapat dilihat pada Gambar 2.

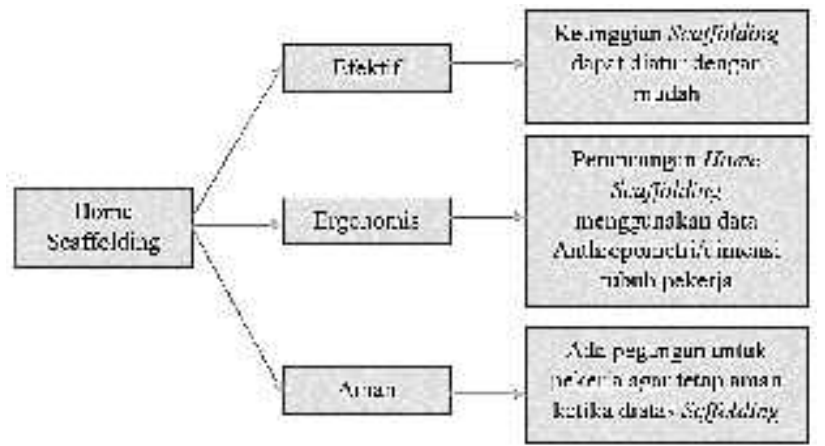

Gambar 2. Objectives Trees Home Scaffolding 


\subsection{Tahap Establishing Function}

Pada tahap ini, metode yang digunakan adalah dengan menggunakan function analysis atau analisis fungsi yang bertujuan untuk menentukan fungsi- fungsi yang dibutuhkan dan batasan sistem dari perancangan alat bantu Home Scaffolding. Function Analysis alat bantu Home Scaffoldig dapat dilihat pada Gambar 3
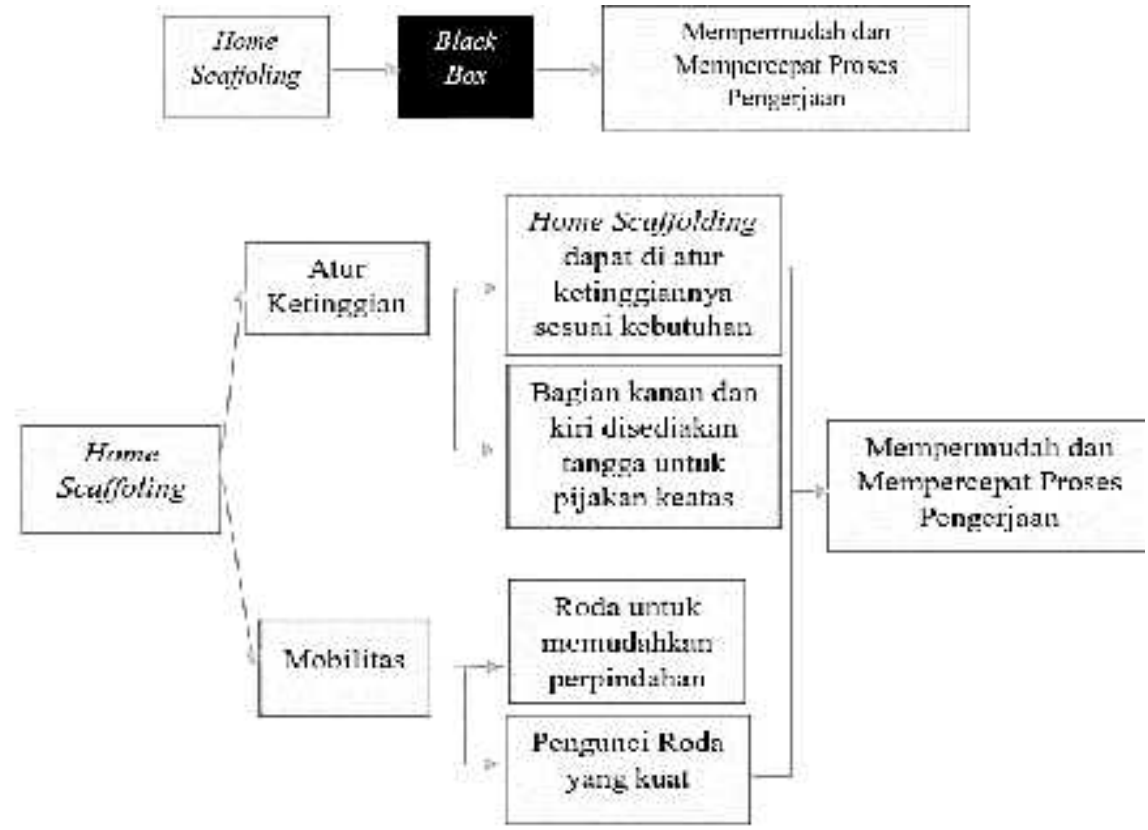

Gambar 3. Function Analysis Home Scaffolding

\subsection{Tahap Setting Requirement}

Pada tahap ini, metode yang digunakan adalah performance spesifications atau spesifikasi performansi untuk membuat spesifikasi yang akurat dari kebutuhan pelaksana suatu solusi perancangan alat Home Scaffolding. Berikut ini adalah spesifikasi performansi alat Home Scaffolding yang dapat dilihat pada Tabel 1.

Tabel 1. Performance Spesification Home Scaffolding

\begin{tabular}{|l|l|}
\hline Tujuan & Kriteria \\
\hline $\begin{array}{l}\text { Mempermudah } \\
\text { proses pengerjaan }\end{array}$ & $\begin{array}{l}\text { Home Scaffolding dapat } \\
\text { di atur ketinggannya dengan mudah, sisi } \\
\text { sampingnya terdapat anak tangga, roda } \\
\text { memudahkan untuk memindahkan }\end{array}$ \\
\hline $\begin{array}{l}\text { Nyaman untuk digunakan selama } \\
\text { bekerja }\end{array}$ & $\begin{array}{l}\text { Menggunakan data antropometri untuk } \\
\text { menentukan dimensi Home } \\
\text { Scaffolding }\end{array}$ \\
\hline $\begin{array}{l}\text { Aman digunakan } \\
\text { selama bekerja }\end{array}$ & $\begin{array}{l}\text { Di bagian atas Home } \\
\text { Scaffolding disediakan pegangan untuk } \\
\text { keamanan pekerja }\end{array}$ \\
\hline
\end{tabular}

\subsection{Tahap Determining Characteristic}

Pada tahapan ini, metode yang digunakan adalah analisis ergonomi dan analisis teknis (Tabel 2). Tahap ini menjelaskan mengenai pemenuhan target yang akan dicapai dari setiap karakteristik produk sehingga dapat memenuhi kebutuhan konsumen.

Tahapan Determining Characteristic pada penelitian ini menggunakan pendekatan Antropometri dan tidak menggunkan Quality Function Deployment sehingga keinginan dari konsumen tetap dipertimbangkan tetapi hanya untuk menentukan kriteria pembobotan dan alternatif-alternatif yang digunakan selama perancangan. 
Tabel 2. Analisis Ergonomi

\begin{tabular}{|l|l|l|l|}
\hline Dimensi & Persentil & \multicolumn{1}{|c|}{ Alasan } & \multicolumn{1}{|c|}{$\begin{array}{c}\text { Ukuran } \\
\text { Perancanaan }\end{array}$} \\
\hline TBT & P50 & $\begin{array}{l}\text { Agar tidak terlalu tinggi dan } \\
\text { tidak terlalu rendah }\end{array}$ & 172 \\
\hline TSB & P5 & $\begin{array}{l}\text { Agar dapat di jangkau } \\
\text { badan tinggi/badan pendek }\end{array}$ & 100 \\
\hline RT & P50 & $\begin{array}{l}\text { Agar penggunaan menjadi lebih } \\
\text { mudah }\end{array}$ & 171 \\
\hline PTT & P5 & $\begin{array}{l}\text { Agar dapat di genggam semua } \\
\text { ukuran tangan }\end{array}$ & 17 \\
\hline LB & P55 & $\begin{array}{l}\text { Agar semua ukuran badan } \\
\text { dapat menggunakan }\end{array}$ & 46 \\
\hline TPO & P5 & $\begin{array}{l}\text { Agar dapat di jangkau semua } \\
\text { kaki panjang/pendek }\end{array}$ & 39 \\
\hline
\end{tabular}

\subsection{Tahap Generating Alternatives}

Pada tahapan ini, metode yang digunakan adalah dengan menggunakan morphology chart atau peta morfologi untuk membangkitkan range masing- masing solusi alternatif dari perancangan yang akan dilakukan dan juga melakukan perluasan terhadap solusi baru yang potensial. Morphology chart perancangan Home Scaffolding dapat dilihat pada Tabel 3:

Tabel 3. Morphology Chart

\begin{tabular}{|l|c|c|c|c|}
\hline \multirow{2}{*}{ Attribut } & \multicolumn{3}{|c|}{ Alternatif } & \multirow{2}{*}{$\begin{array}{c}\text { Jumlah } \\
\text { alternatif }\end{array}$} \\
\cline { 2 - 4 } & 1 & 2 & 3 & 3 \\
\hline $\begin{array}{l}\text { Kerangka } \\
\text { Utama }\end{array}$ & Aluminium & Besi & Stainless & 3 \\
\hline $\begin{array}{l}\text { Lapisan Anak } \\
\text { Tangga }\end{array}$ & Busa & Karet & & 2 \\
\hline $\begin{array}{l}\text { Pegangan } \\
\text { Pengaman }\end{array}$ & Aluminium & Besi & & 2 \\
\hline $\begin{array}{l}\text { Pijakan } \\
\text { Scaffolding }\end{array}$ & Aluminium & Besi & & 2 \\
\hline
\end{tabular}

\subsection{Tahap Evaluating Alternatives}

Pada tahapan ini, metode yang digunakan adalah metode weighted objectives yang berisi penjelasan mengenai perbandingan nilai alternative usulan dari perancangan alat. Hal yang pertama harus dilakukan adalah screening, tahapan ini digunakan untuk mengurangi jumlah alternatif yang muncul dari perancangan Home Scaffolding. Alternatif yang muncul pada tahap Generating Alternatives adalah sebanyak 24 alternatif dan dilakukan pengurangan terhadap alternatif- alternatif tersebut. Pengurangan alternatif dilakukan berdasarkan penilaian terhadap karakter dari material yang diakomodasikan pada tahap generating alternatives. Berikut ini merupakan keterangan pertimbangan penghapusan beberapa alternatif dari tahap sebelumnya yang dapat dlihat pada Tabel 4.

Tabel 4. Hasil Screening Morphology Chart

\begin{tabular}{|l|l|l|c|}
\hline \multirow{2}{*}{ Atribut } & \multicolumn{2}{c|}{ Alternatif } & Jumlah \\
\cline { 2 - 3 } & \multicolumn{1}{c|}{$\mathbf{2}$} & Alternatif \\
\hline Kerangka Utama & Aluminium & Besi & 2 \\
\hline Lapisan Anak & Busa & Karet & 2 \\
\hline Tanaangan Pengaman & Aluminium & Besi & 2 \\
\hline Pegangakan Scaffolding & Aluminium & Besi & 2 \\
\hline
\end{tabular}


Pembobotan dalam hal ini berdasarkan pada nilai rata-rata hasil preferensi responden terhadap masing- masing kriteria pada kuisioner. Kriteria dengan nilai rata-rata terbesar akan mendapatkan rangking tertinggi dan memiliki bobot terbesar. Pada tahap ini dilakukan Focus Group Discusion (FGD) yang terdiri dari 5 orang dengan peran sebagai perancang atau orang bengkel sebanyak 2 orang, peneliti 2 orang, dan 1 operator mesin yang terbiasa menggunakan alat sejenis. Dari hasil FGD dihasilkan hasil untuk pembobotan objektif yang dapat dilihat pada Tabel 5.

Tabel 5. Pembobotan Setiap Kriteria

\begin{tabular}{|l|l|c|c|c|c|}
\hline No & Kriteria & Rata-rata & Ranking & Nilai & Bobot \\
\hline $\mathbf{1}$ & $\begin{array}{l}\text { Konstruksi Home Scaffolding } \\
\text { Kuat dan Tahan Lama }\end{array}$ & 4,6 & 1 & 3 & 0,500 \\
\hline $\mathbf{2}$ & $\begin{array}{l}\text { Home Scaffolding Aman Saat } \\
\text { Digunakan }\end{array}$ & 4,2 & 3 & 1 & 0,167 \\
\hline $\mathbf{3}$ & $\begin{array}{l}\text { Konstruksi Home Scaffolding } \\
\text { Disesuaikan Dengan Antropometri } \\
\text { Tubuh Pekerja }\end{array}$ & 4,4 & 2 & 2 & 0,333 \\
\hline \multicolumn{2}{|c|}{ Total } & 6 & 6 & 1 \\
\hline
\end{tabular}

Pada tahap penilaian ini dilakukan pemberian nilai terhadap masing-masing kriteria dalam Weighted Objectives Evaluation Chart untuk memilih salah satu dari 16 alternatif usulan perancangan Home Scaffolding. Nilai yang diperoleh untuk masing- masing kriteria merupakan hasil perkalian antara nilai bobot dan nilai skor. Penilaian dulakukan dengan menggunakan skala 5 titik dengan skala dimulai dari 0 sampai 4 .

Kriteria 1: Konstruksi Home Scaffolding kuat dan tahan lama. Atribut yang digunakan untuk memenuhi kriteria konstruksi Home Scaffolding kuat dan tahan lama

Kriteria 2: Home Scaffolding aman saat digunakan. Atribut yang digunakan untuk memenuhi kriteria Home Scaffolding aman saat digunakan

Kriteria 3: Konstruksi Home Scaffolding disesuaikan dengan antropometri tubuh pekerja. Pada kriteria ketiga ini semua alternatif diberikan skor 4 karena semua alternatif disesuaikan dengan data antropometri yang diperoleh dari data pada tahap sebelumnya.

Setelah mengetahui skor masing-masing kriteria, tahapan selanjutnya adalah menghitung bobot total dari masing-masing alternatif untuk mencari alternatif yang memiliki bobot terbesar untuk dijadikan sebagai alternatif terbaik. Berdasarkan hasil penilaian alternatif diatas, hasil perkalian dari bobot dan skor yang tertinggi adalah pada altenatif ke 5 , yaitu sebesar 4. Hasil tersebut akan digunakan sebagai acuan untuk perancangan Home Scaffolding yang akan direalisasikan. Berikut ini adalah alternatif perancangan Home Scaffolding yang akan direalisasikan (Tabel 6).

Tabel 6. Alternatif Terbaik

\begin{tabular}{|l|l|c|}
\hline Kerangka Utama & Aluminiu & 4 \\
\hline $\begin{array}{l}\text { Lapisan Anak } \\
\text { Tangga }\end{array}$ & Karet & 4 \\
\hline $\begin{array}{l}\text { Pegangan } \\
\text { Pengaman }\end{array}$ & $\begin{array}{l}\text { Aluminiu } \\
\mathrm{m}\end{array}$ & 4 \\
\hline Pijakan Scaffolding & Aluminiu & 4 \\
\hline
\end{tabular}

\subsection{Tahap Improving Detail}

Tahap improving details merupakan tahapan terakhir dari perancangan ini, pada tahap ini menggunakan metode perbandingan antara produk terdahulu dengan hasil rancangan, yaitu hasil perbandingan scaffolding dengan Home Scaffolding.

\subsection{Simulasi Produk}

Pada penelitian ini melakukan rekayasa percobaan untuk mengetahui kekuatan produk Home Scaffolding bila di beri sebuah gaya. Simulasi produk Home Scaffolding 
menggunakan bantuan software Autodesk Inventor Professional 2016. Hasil dari percobaan simulasi dengan besar gaya 3000 Newton atau 305,93 kg produk Home Scaffolding tidak mampu menahan beban yang diterima, mengakibatkan lengkungan dan beberapa patahan. Percobaan ini menunjukan bahwa Home Scaffolding dengan material Aluminium dapat menahan gaya $0<3000$ Newton, maka Home Scaffolding mampu dan aman di gunakan ketika di beri gaya $(\omega=\mathrm{m} . \mathrm{g})$ sebesar $0<2500 \mathrm{~N}$ atau $0<254,94 \mathrm{Kg}$, dengan rata-rata berat badan indonesia sebesar $76 \mathrm{~kg}$ yang berarti Home Scaffolding aman digunakan sekitar 1-3 orang (percepatan gravitasi $9,806 \mathrm{~m} / \mathrm{s} 2$ ), pemberian allowance 500 Newton dikarenakan dengan berjalannya waktu bila material di beri beban mendekati titik maksimalnya akan membahayakan pengguna.

\subsection{Rancangan Produk}

Berikut adalah rancangan produk Home Scaffolding yang telah dibuat dengan menggunakan metode rasional dan pendekatan anthropometri.

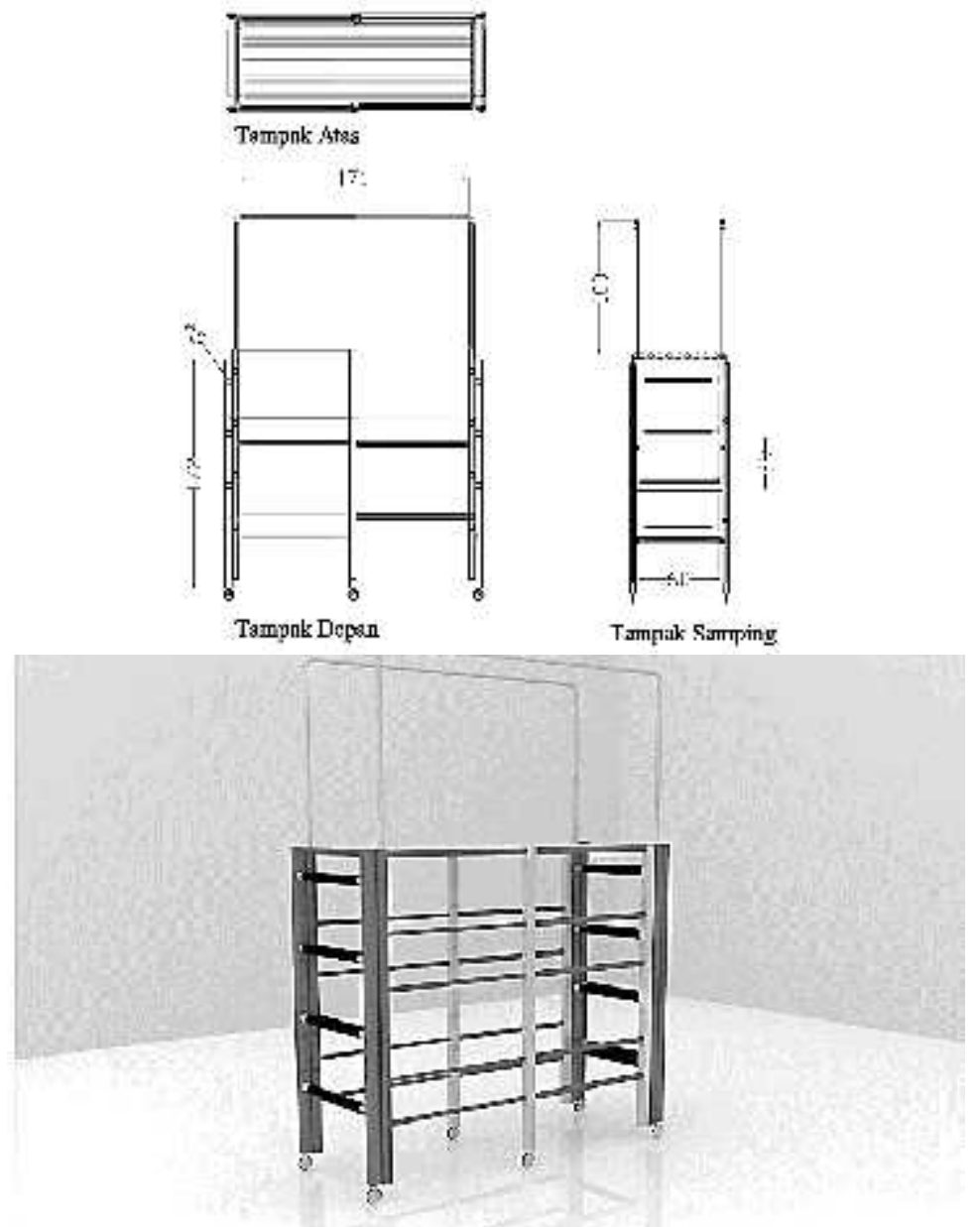

Gambar 4. Desain Home Scaffolding

\section{Kesimpulan}

Berdasarkan hasil analisis dan pembahasan yang dilakukan maka diperoleh kesimpulan sebagai berikut: Home Scaffolding dengan desain baru yang sesuai dengan kebutuhan adalah scaffolding yang dapat diatur ketinggiannya sesuai dengan kebutuhan, dapat dilipat untuk menghemat tempat, ringan dan mudah di bawa kesegala medan, dan rancangan desain disesuaikan dengan Anthropometri postur tubuh masyarakat Indonesia. Dengan menggunakan Metode Rasional didapatkan material terbaik untuk perancangan Home Scaffolding, yaitu kerangka utama terbuat dari Aluminium, lapisan anak tangga berbahan karet, pegangan pengaman terbuat dari Aluminium, dan pijakan terbuat 
dari Aluminium. Dengan melakukan uji simulasi produk Home Scaffolding yang di beri material Aluminium, dapat menahan beban gaya sebesar $0<2500$ Newton yang berarti Home Scaffolding mampu menahan dan aman digunakan hingga 3 orang yang berada di atasnya.

\section{Referensi}

[1] Nurmianto, E.2004. Ergonomi Konsep Dasar dan Aplikasinya. Guna Widya. Edisi Pertama. Cetakan Keempat. Surabaya.

[2] Wibowo, Bagas Prasetyo. 1999. Desain Produk Industri. Yayasan Delapan Sepuluh: Bandung.

[3] Kotler, Philip. 2001. Manajemen Pemasaran: Analisis, Perencanaan, Implementasi dan Kontrol. Jakarta: PT. Prehallindo.

[4] Ramdhani, Safarudin. 2013. Perancangan Alat Pengupas Kulit Melinjo. Skripsi. Universitas Dian Nuswantoro, Semarang.

[5] Susanto, Adi. 2014. Perancangan Meja Kerja Untuk Alat Pres Plastik Yang Ergonomis Mengunakan Metode Rasional dan Pendekatan Anthropometri. Skripsi. Universitas Dian Nuswantoro, Semarang. 